\title{
COMPULSIVE INTERNET USE AND ACADEMIC PROCRASTINATION: SIGNIFICANT COMPARATIVE, CORRELATIVE AND PREDICTING INDICATORS IN A ROMANIAN STUDENT SAMPLE
}

\author{
Adrian Tudor BRATE \\ "Lucian Blaga" University of Sibiu, Romania \\ adrian.brate@ulbsibiu.ro
}

\begin{abstract}
The purpose of this study was to investigate significant measures between indicators / factors associated to compulsive Internet use and academic procrastination behaviors, for a sample of students, from Romanian education institutions.

Previous transcultural findings indicate that compulsive Internet use and procrastination behaviours, but in most cases investigated separately, can interfere, distract, delay and / or have a negative impact on academic work / achievement (completing reading assignments, homework, studying for exams / academic failure), task performance and quality of life (personal and social obligations).

Romanian participants were asked on a voluntary basis and with informed consent to complete demographic data and questionnaires about internet use (the Romanian translated and adapted version of The Compulsive Internet Use Scale, CIUS, developed by Meerkerk, G.-J., Van Den Eijnden, R. J. J. M., Vermulst, A. A., \& Garretsen, H. F. L., 2009 [4] [5]) and procrastination behaviors (the Romanian translated and adapted version of The Procrastination Assessment Scale - for Students, PASS, designed by Solomon and Rothblum, 1984 [8] [9]). They also were informed that their responses are confidential: 211 valid surveys from 111 college undergraduates and 100 high-school students were collected for analysis.

Results identified significant comparative data and correlative indicators of compulsive Internet use in predicting specific procrastination behaviors, for the 211 participants.

Implications and future methodological research and coping strategies of this topic were discussed.
\end{abstract}

Keywords: Compulsive internet use, academic procrastination, indicators, Romanian students

\section{Introduction}

Previous transcultural findings and metaanalytic studies [1] [2] [3] [4] [6] [7] [8] [10] [11] indicate that compulsive Internet use and procrastination behaviours, but in most cases investigated separately, can interfere, distract, delay and/ or have a negative impact on academic work/ achievement (completing reading assignments, homework, studying for exams / academic failure), task performance and quality of life (personal and social obligations).

\section{Method}

\subsection{Objectives}

The objectives of the study are:

- To explore the differences among highschool and university students, female vs. male participants on variables of procrastination;

- To examine differences about selfreported internet use and variables of academic procrastination (reasons);

- To identify possible significant predictors/ correlations on the reported internet use and procrastination variables;

\subsection{Participants and instruments}

Romanian participants were asked on a 
voluntary basis and with informed consent to complete demographic data and questionnaires about internet use (the Romanian translated and adapted version of The Compulsive Internet Use Scale, CIUS, developed by Meerkerk, G.-J., Van Den Eijnden, R. J. J. M., Vermulst, A. A., \& Garretsen, H. F. L., 2009 [4] [5]) and procrastination behaviors (the Romanian translated and adapted version of The Procrastination Assessment Scale - for Students, PASS, designed by Solomon and Rothblum, 1984 [8] [9]). They also were informed that their responses are confidential: 211 valid surveys from 111 college/ university undergraduates (94 females and 17 males, with age between 1936) and 100 high-school students (75 females and 25 males, with age between 1819) were collected for analysis.

\section{Results}

The data were processed through a specialized statistical program. In the data processing, first, descriptive statistical values on mean differences have been obtained, then, significant correlations and regression analysis models (predictors) between the measured variables, were explored.

\subsection{Descriptive analysis}

Relevant descriptive and comparative data have been selected. Regarding the exploration of significant differences among high-school and university students, female vs. male participants on selfreported internet use and variables of academic procrastination (motivations) we can conclude that:

- The university student sample scored higher than the high school student sample on: self-reported procrastination $(\mathrm{p}<.04)$ and the following procrastination reasons: fear of failure $(p<.003)$, aversiveness of task $(p<.01)$; difficulty making decision $(p<.003)$; time management $(p<.002)$; lack of assertion $(p<.004)$, low self-esteem $(p<.005)$, laziness $(p<.02)$, perfecţionism $(p<.0001)$;
- Female than male students scored higher on the following procrastination reasons: dependency $(p<.02)$, time management $(p<.006)$ and lower on: risk taking $(p<.02)$, peer pressure $(p<.005)$;

- No significant differences have been reported regarding the university student sample vs. the high school student sample on: the self-reported CIUS score and the following procrastination reasons: evaluation anxiety, dependency, rebellion against control, risk taking, fear of succes and peer pressure;

- No significant differences have been reported regarding feminine vs. masculine participants on: the self-reported CIUS score and the self-reported PASS score;

\subsection{Correlational analysis and models of regression analysis}

In this section, a selection of significant correlations/ associations between the measured variables is presented:

- Gender with reasons for procrastination: dependency $\quad r=-.15 \quad(\mathrm{p}<.05), \quad$ time management $r=-.18 \quad(\mathrm{p}<.01)$, risk taking $r=.15 \quad(\mathrm{p}<.05)$ and peer pressure $r=.19$ $(p<.01)$ - female students tend to use more often as reasons for procrastination: dependency and time management;

- The age of participants with the selfreported score of procrastination $r=.15$ $(p<.05)$ and the following reasons for procrastination: fear of failure $r=.14$ $(\mathrm{p}<.05)$, risk taking $r=.22(\mathrm{p}<.01)$ and fear of succes $r=.15(\mathrm{p}<.05)-$ at "older" ages students tend to develop procrastination behavior and report especially the fear of failure, risk taking and fear of succes, as reasons for procrastination;

- The self-reported CIUS (compulsive internet use) score with the following reasons for procrastination: fear of failure $r=.27(\mathrm{p}<.01)$, aversiveness of task $r=.22$ $(p<.01)$, evaluation anxiety $r=.25(p<.01)$, time management $r=.14(\mathrm{p}<.05)$, rebellion against control $r=.14(\mathrm{p}<.05)$, fear of succes $r=.19(\mathrm{p}<.01)$, laziness $r=.18(\mathrm{p}<.01)$, peer pressure $r=.16(\mathrm{p}<.05)$ and perfectionism $r=.18(\mathrm{p}<.01)$; 
- The self-reported procrastination score with reasons for procrastion: fear of failure $r=.23(p<.01)$, aversiveness of task $r=.36$ $(\mathbf{p}<.01)$, time management $r=.18(\mathrm{p}<.01)$, rebellion against control $r=.20(\mathrm{p}<.01)$, low self-esteem $r=.15(\mathrm{p}<.05)$, fear of succes $r=.19(\mathrm{p}<.01)$, laziness $r=.41(\mathbf{p}<.01)$, peer pressure $r=.17(\mathrm{p}<.05)$ and perfectionism $r=.23(p<.01)$;

To identify and test models of prediction regarding internet use and procrastination, or predictor patterns for reasons/ motivations of procrastination in relation to internet use, regression analysis, for explanatory purposes was applied (a selection is presented).
Table 1 present a model of regresssion analysis, where the internet use (compulsive internet use score) is a significant predictor for procrastination behavior (self-reported PASS score).

Table 2 and 3 show two possible models/ types of student behavior, in which the combined reasons for procrastinationn (fear of failure and aversiveness of task or fear of failure and laziness) are significant predictors for self-reported procrastination. In table 4 another pattern of behavior could be identified: fear of failure and laziness (procrastination reasons), as significant predictors for the tendence of compulsive internet use.

Table 1 Internet use as predictor for Procrastination Behavior

\begin{tabular}{|l|l|c|c|c|c|c|}
\hline \multicolumn{7}{|c|}{ Coefficients $^{\mathbf{2}}$} \\
\multicolumn{2}{|l|}{ Model } & Unstandardized Coefficients & Standardized Coefficients & \multirow{2}{*}{ Sig. } \\
\cline { 3 - 8 } \multicolumn{2}{|l|}{1} & B & Std. Error & Beta & & \\
\hline \multirow{2}{*}{1} & (Constant) & 27.421 & 3.613 & & 17.512 & $\mathbf{. 0 0 0}$ \\
\cline { 2 - 8 } & CIUS & .176 & .041 & $\mathbf{. 2 8 4}$ & 4.289 & .000 \\
\hline
\end{tabular}

a. Dependent Variable: Self-reported Procrastination

Table 2 Fear of failure and aversiveness of task as predictors for Procrastination Behavior

\begin{tabular}{|c|c|c|c|c|c|c|}
\hline \multicolumn{7}{|c|}{ Coefficients $^{\mathrm{a}}$} \\
\hline \multirow{2}{*}{\multicolumn{2}{|c|}{ Model }} & \multicolumn{2}{|c|}{$\begin{array}{l}\text { Unstandardized } \\
\text { Coefficients }\end{array}$} & $\begin{array}{l}\text { Standardized } \\
\text { Coefficients }\end{array}$ & \multirow[t]{2}{*}{$\mathrm{t}$} & \multirow[t]{2}{*}{ Sig. } \\
\hline & & $\mathrm{B}$ & Std. Error & Beta & & \\
\hline \multirow{3}{*}{1} & (Constant) & 25.094 & 1.531 & & 16.395 & .000 \\
\hline & Fear of failure & .250 & .103 & .160 & 2.350 & .016 \\
\hline & Aversiveness of task & .753 & .152 & .325 & 4.963 & .000 \\
\hline
\end{tabular}

Table 3 Fear of failure and laziness of task as predictors for Procrastination Behavior

\begin{tabular}{|c|c|c|c|c|c|c|}
\hline \multicolumn{7}{|c|}{ Coefficients $^{\mathrm{a}}$} \\
\hline \multirow{3}{*}{\multicolumn{2}{|c|}{ Model }} & \multirow{2}{*}{\multicolumn{2}{|c|}{$\begin{array}{c}\text { Unstandardized } \\
\text { Coefficients }\end{array}$}} & Standardized & \multirow[t]{3}{*}{$\mathrm{t}$} & \multirow[t]{3}{*}{ Sig. } \\
\hline & & & & Coefficients & & \\
\hline & & $\mathrm{B}$ & Std. Error & Beta & & \\
\hline \multirow{3}{*}{1} & (Constant) & 23.196 & 1.545 & & 15.014 & .000 \\
\hline & Fear of failure & .331 & .097 & .211 & 3.423 & .016 \\
\hline & Laziness & 1.163 & .179 & .399 & 6.481 & .000 \\
\hline
\end{tabular}

a. Dependent Variable: Self-reported Procrastination 
Table 4 Fear of failure and laziness of task as predictors for Internet use

\begin{tabular}{|c|c|c|c|c|c|c|}
\hline \multicolumn{7}{|c|}{ Coefficients $^{\mathrm{a}}$} \\
\hline \multirow{2}{*}{\multicolumn{2}{|c|}{ Model }} & \multicolumn{2}{|c|}{$\begin{array}{l}\text { Unstandardized } \\
\text { Coefficients }\end{array}$} & \multirow{2}{*}{$\begin{array}{c}\text { Standardized Coefficients } \\
\text { Beta }\end{array}$} & \multirow[t]{2}{*}{$\mathrm{t}$} & \multirow[t]{2}{*}{ Sig. } \\
\hline & & B & Std. Error & & & \\
\hline \multirow{3}{*}{1} & (Constant) & 24.387 & 2.662 & & 9.160 & .000 \\
\hline & Fear of failure & .665 & .167 & .263 & 3.994 & .000 \\
\hline & Laziness & .791 & .309 & .168 & 2.559 & .011 \\
\hline
\end{tabular}

a. Dependent Variable: Self-reported compulsive internet use CIUS

\section{Conclusion and discussion}

The use of internet in a compulsive manner and procrastination behavior with its diverse forms and motivations is a prevalent and current phenomenon for different kind of student-level and academic setting. The participants of this study were university and high-school students, who are planning to enter into occupational life and career development, therefore the measurable behaviours discussed above are highly influential for them, regarding academic/ professional performance.

The results have identified specific demographic differences regarding variables of internet use and procrastination, also significant correlations, predictors and models of regression have been identified for the romanian participants.

But still, there is a need to explore new forms and motivations of procrastination behavior in relation to compulsive internet use, which can influence the academic settings and the quality of life. The question remains: does the extreme internet use (with specific or diverse content) influence/ trigger procrastination behaviors, forms and motivations or viveversa? Or is it a vicious cycle? What can be done for intervention and prevention at different institutional/ organisational or personal/ family levels?

\section{Implications}

The results of the study have some practical implications and made us think about focalized solutions. A lot of students encounter nowadays lots of academic problems, because of their thoughts, emotions and behaviors, about procrastination and internet use. Many students declare to be conscious of their procrastination and reported that they want to decrease its frequency in their daily routine.

We suggest that more and more education institutions/ organizations should focus on:

- Developing intervention programmes and organizing workshops for managing procrastination, internet use, efficient time management, academic motivation and task oriented coping strategies, at individual and group level;

- Stimulating and improving the tutorship and didactical teaching strategies (grounded learning);

Future interventions, for lowering the personal and global costs to health and well-being, should also focus on reducing the use of avoidant, self-blaming and compulsive substance/ internet use coping among procrastinators and stimulate learning strategies for proactive coping [7], which involves taking a future-oriented and problem-focused approach.

\section{Acknowledgements}

I would like to express my great appreciation and special thanks to Miss Crina Lavinia PAŞTIU, former student of mine, for giving me the permission to use data from the Romanian translated and adapted versions of CIUS and PASS. 


\section{References}

[1] Guertler D. et al., Factor Structure of the Compulsive Internet Use Scale, CYBERPSYCHOLOGY, BEHAVIOR, AND SOCIAL NETWORKING, Volume 17, Number 1, 2014, DOI: 10.1089/cyber.2013.0076.

[2] Kim, K.R. \& Seo, E.H, The relationship between procrastination and academic performance: A meta-analysis. Personality and Individual Differences, 82, pp 26-33, 2015.

[3] Klassen R. M., Krawchuk, L. L. \& Rajani S., Academic procrastination of undergraduates: Low self-efficacy to self-regulate predicts higher levels of procrastination, Contemporary Educational Psychology, 33, 915-93, 2008.

[4] Meerkerk G.-J. et al., The Compulsive Internet Use Scale (CIUS): Some Psychometric Properties, CYBERPSYCHOLOGY \& BEHAVIOR, Volume 12, Number 1, 2009, DOI: $10.1089 / \mathrm{cpb} .2008 .0181$

[5] Meerkerk, G.-J. et al., Compulsive Internet Use Scale [Database record]. Retrieved from PsycTESTS. doi: http://dx.doi.org/10.1037/t34789-000, 2009.

[6] Sirois F. M., Out of Sight, Out of Time? A Meta-analytic Investigation of Procrastination and Time Perspective, European Journal of Personality, Eur. J. Pers. 28: 511-520, 2014, DOI: 10.1002/per.1947.

[7] Sirois F. M. \& Kitner, R., Less Adaptive or More Maladaptive? A Meta-analytic Investigation of Procrastination and Coping, European Journal of Personality, Eur. J. Pers. 29: 433-444, 2015, DOI: 10.1002/per.1985.

[8] Solomon, L.J. \& Rothblum E.D., Academic Procrastination: Frequency and CognitiveBehavioral Correlates, Journal of Counseling Psychology, Vol. 31, No. 4, pp. 503-509, 1984.

[9] Solomon, L. J., \& Rothblum, E. (1984). Procrastination Assessment Scale--Students [Database record]. Retrieved from PsycTESTS. doi: http://dx.doi.org/10.1037/t09250000 .

[10] Steel, P., The Nature of Procrastination: A Meta-Analytic and Theoretical Review of Quintessential Self-Regulatory Failure, Psychological Bulletin, Vol. 133, No. 1, 65-94, 2007, DOI: 10.1037/0033-2909.133.1.65.

[11] Vij J. \& Lomash H., Role of Motivation in Academic Procrastination, International Journal of Scientific \& Engineering Research, Volume 5, Issue 8, August-2014, ISSN 2229-5518. 